\title{
Nanomaterials in the application of tumor vaccines: advantages and disadvantages
}

This article was published in the following Dove Press journal:

OncoTargets and Therapy

4 June 2013

Number of times this article has been viewed

\author{
XD Li ${ }^{2, *}$ \\ JY Gaol,* \\ Y Yangl,* \\ HY Fang' \\ YJ Han' \\ XM Wang' \\ $W \mathrm{Ge}^{1}$ \\ 'Department of Geriatrics, \\ ${ }^{2}$ Department of Equipment, Xijing \\ Hospital, Fourth Military Medical \\ University, Xi'an, People's Republic \\ of China \\ *These authors contributed equally \\ to this work
}

Correspondence: W Ge, XM Wang Department of Geriatrics, Xijing Hospital, Fourth Military Medical University, Changle West Road, Xi'an, Shaanxi Province 710032, People's Republic of China

Email geweidr@fmmu.edu.cn, xmwang@fmmu.edu.cn

\begin{abstract}
Tumor vaccines are a novel approach to the treatment of malignancy, and are attracting the attention of the medical profession. Nanomaterials have significant advantages in the preparation of a tumor vaccine, including their ability to penetrate and target cancer tissue and their antigenic properties. In this review, we focus on several nanomaterials, ie, carbon nanotubes, nanoemulsions, nanosized aluminum, and nanochitosan. Applications for these nanomaterials in nanovaccines and their biological characteristics, as well as their potential toxicity, are discussed.
\end{abstract}

Keywords: nanomaterials, tumor vaccine, carbon nanotubes, nanoemulsions, nanosized aluminum, nanochitosan

\section{Introduction}

Increasing attention is being paid to tumor vaccines as a novel antineoplastic therapy that can be used against tumor cells, tumor cell lysates, and tumor antigens to activate the immune system and produce a specific antitumor immune effect. ${ }^{1,2}$ Tumor vaccines are derived from autologous or allogeneic tumor cells or a crude extract with a tumorspecific or tumor-associated antigen. ${ }^{3}$ These vaccines can stimulate specific immune mechanisms to attack tumor cells and overcome the immune suppression caused by tumor products, thereby enhancing the immunogenicity of tumor-associated antigens and helping the immune system to destroy the tumor. ${ }^{4}$

The ideal vaccine would be a simple formulation, easy to manufacture, stable over a range of ambient temperatures, conveniently administered, readily transported, able to provide lifelong immunity against a given pathogen, and inexpensive. , $^{5,6}$

Basic particles of natural or artificial materials are used to compose nanostructures. The three-dimensional size of these particles is in the range of $1-100 \mathrm{~nm}$. The total number of elementary particles should be more than $50 \%$ of all particles in the material. ${ }^{7}$ Nanomaterials have special thermodynamic, mechanical, magnetic, optical, and quantum properties, and their use in the preparation of tumor vaccines has enabled controlled release, stability, targeting, magnetic properties, greater penetration, and antigenic features to be incorporated..$^{8-10}$ These characteristics make antitumor nanovaccines very promising for the prevention and treatment of cancer. ${ }^{11}$

Nanomaterials combined with tumor antigens allow tumor vaccines to have stronger biocompatibility, permeability, and targeting properties. Nanomaterials themselves are antigenic and can stimulate a strong immune response in the human body. ${ }^{12}$ In the future, as nanoscience and nanotechnology make more progress, and more 
new nanomaterials continue to appear, they will be used increasingly in the field of tumor vaccines. ${ }^{13}$

There have also been some reports on the toxicity of nanomaterials. ${ }^{14}$ Nanomaterials may become attached to the surfaces of biological membranes by adsorption or electrostatic effects, causing damage to cells by generating reactive oxygen species, resulting in lipid peroxidation, protein denaturation, DNA damage, and ultimately cell death. ${ }^{15-17}$ For example, multiwalled carbon nanotubes (CNT) are toxic to the immune system in mice, ${ }^{18}$ and can cause inflammation and damage to lung tissue. ${ }^{19}$ With the probable extensive application of nanomaterials in the future, the possibility of a negative impact of nanomaterials on humans cannot be ignored.

\section{Carbon nanotubes}

Carbon nanotubes formed by aggregation of single carbon atoms under certain conditions, ${ }^{20}$ have been used as carriers for a dendritic cell tumor vaccine. A dendritic cell tumor vaccine was created in vitro, whereby different amounts of tumor protein antigens against dendritic cells were loaded into CNT, and used to stimulate the immune system to produce more $\mathrm{T}$ cells, with the aim of destroying the tumor. CNT were connected with tumor proteins by formation of a covalent bond with tumor polypeptides or formation of complexes between CNT and tumor proteins. ${ }^{21}$ The CNT promotes phagocytosis of dendritic cells in the tumor tissue, such that more antigens to the dendritic cell are produced, significantly enhancing the immunogenicity of proteins in the tumor. ${ }^{22}$ Thus, the ability of lymphocytes to attack and destroy the tumor are enhanced by activation using CNT-tumor protein complexes. ${ }^{23,24}$ In addition, the CNT-tumor protein complex is directly stimulated by the lymphocytes themselves, which further increases the ability of lymphocytes to destroy tumor cells. A foot and mouth disease virus polypeptide attached to CNT has been used to immunize BALB/c mice, and induced a strong antibody response. ${ }^{25}$ Multiwalled CNT conjugated with tumor lysate protein was shown to enhance the efficacy of immunotherapy using a tumor cell vaccine in a mouse model of H22 liver cancer.

\section{CNT as tumor vaccine vectors}

Most biological macromolecules, including proteins, cannot enter cells because of the selective permeability of the cell membrane, which has hampered application of tumor vaccines. ${ }^{26}$ DNA molecules, nucleic acids, proteins, and other biological molecules are adsorbed onto the outer wall of CNT via electrostatic and hydrophobic interactions. ${ }^{27,28}$ The biological activity of these macromolecules can be retained and maximized by nonspecific interactions with CNT. ${ }^{29,30}$ The CNT then pass into cells via dissipation of passive energy and receptor-mediated endocytosis. ${ }^{31}$ Another theory is that diffusion of CNT into cells is an active process occurring at the phospholipid bilayer of the cell membrane. ${ }^{32}$ CNT can be loaded with tumor-specific antigens by forming stable covalent bonds or supramolecular assemblies based on noncovalent interactions. Once this cargo has been transported into various cells, tissues, and organs, the tumor-specific antigens are able to carry out their biological function. ${ }^{33}$ There has been a report of single-walled CNT being used as antigen carriers, whereby Wilms' tumor antigen was solubilized onto single-walled CNT scaffolds which were rapidly internalized into antigen-presenting cells for recognition by T cells. ${ }^{34}$ In summary, CNT are ideal carriers for tumor vaccines.

\section{Toxicity of CNT}

Incorporation of nanomaterials in tumor vaccines has many advantages, but their potential toxicity cannot be ignored. ${ }^{35}$ Epidemiological studies have shown that nanoparticles cause cardiovascular and respiratory disease, and can pass through the blood-brain barrier into the nervous system, leading to a variety of neurological disorders. ${ }^{36,37}$ In vitro studies have shown that CNT have many toxic effects, including decreased cell viability, induction of apoptosis, disruption of the cell cycle, and generation of oxidative stress and inflammatory responses. ${ }^{38-40} \mathrm{CNT}$ can damage the respiratory system of mice by entering the alveolar space, causing a chronic inflammatory reaction characterized by intermittent granulomatous lung tissue and finally pulmonary fibrosis, with significantly greater toxicity than that seen with ordinary carbon black. ${ }^{41,42}$ CNT distribute throughout the body via the circulatory and lymphatic systems in mice; therefore, their toxicity is not limited to the site of administration. ${ }^{43}$ It is possible that CNT have toxic effects in several organ systems. It has been confirmed that CNT pass through the blood-brain barrier into the central nervous system in mice, ${ }^{44}$ and neuronal apoptosis due to peroxide-induced inflammation and oxidative stress in stimulated neurons and glial cells has been observed. ${ }^{45,46}$

CNT makes protein adhesive modified, so the tumor antigen in it will be affected, resulting in immune activity reduced. Furthermore, the carbon nanotubes are difficult to be degraded in vivo, may be deposited within macrophages as the formation of localized granuloma. ${ }^{47,48}$ 


\section{Nanoemulsions}

The term Nanoemulsion (NE) means the emulsion diameter of droplets at the nanoscale. A nanoemulsion is created by two immiscible liquids with a thermodynamically stable isotropic appearance in a transparent or translucent dispersion system, ${ }^{49}$ and can be divided into oil-in-water $(\mathrm{o} / \mathrm{w})$, water-in-oil (w/o), and bicontinuous types. ${ }^{50}$ Nanoemulsions have several advantages as parcel carriers for a tumor vaccine, because they have a strong affinity for the lymphatic system, which means they can be directed to the lymphatic circulation where they gather in regional lymph nodes; further, nanoemulsions stimulate lymphocytes to proliferate as part of specific immune responses in local lymph nodes.$^{51}$ In addition, nanoemulsions enhance the bioavailability of a tumor antigen by ensuring its sustained release, particularly in the case of a w/o nanoemulsion, where the surface of the outer oil reservoir acts to partition and protect the contents from the destructive effects of enzymes. ${ }^{52,53}$ Lastly, the process used to form nanoemulsions is safe and does not alter the biological activity of the polypeptide ingredients. ${ }^{54}$

A novel $\mathrm{o} / \mathrm{w}$ nanoemulsion has been used to prevent influenza, and w/o nanoemulsions have been the subject of research as vaccines for acquired immune deficiency syndrome and as immunotherapy for cancer. ${ }^{55,56} \mathrm{~A}$ nanoemulsion encapsulating MAGE1-HSP70 (melanoma associated antigen-hot shock protein)/super antigen staphylococcal enterotoxin $\mathrm{A})^{57-59}$ showed good physicochemical properties, and was found to stimulate strong MAGE-1-specific cellular immunity and prevent expression of MAGE-1 tumor cell attacks in a mouse model. ${ }^{59}$

However, preparation of nanoemulsions remains difficult, given the lack of a standardized method, tumor antigen efficiency is not high, and their use is still confined to animal experiments. ${ }^{60}$ Further, the mechanism explaining the lack of an immune response to MAGE-1 administered via an oral nanoemulsion is not entirely clear. ${ }^{52}$

\section{Adjuvant nanosized aluminum}

Aluminum hydroxide and aluminum phosphate were first approved for use as adjuvant therapy more than 70 years ago. ${ }^{61}$ These adjuvants are widely used in animal and human vaccines. ${ }^{62,63}$ When aluminum is used as an adjuvant for tumor vaccines, it is inexpensive, safe, and easy to prepare, and absorbs tumor proteins. However, aluminum adjuvants are neurotoxic, with allergic reactions at the injection site being common, along with poor antitumor cell immune function. ${ }^{63,64}$
Nanoaluminum compares well with ordinary aluminum as a tumor vaccine adjuvant because of its particle size, specific surface area, and strong adsorption capacity, that can enhance its adjuvant activity while improving targeted antigen delivery and reducing side effects; these advantages have taken nanoaluminum in promising research directions. ${ }^{65}$ Adjuvant nanoaluminum immunotherapy induced strong humoral and cellular immunity against tumors in experiments using viral vaccines in a mouse model. The tumors were significantly reduced in size and strong effects on peripheral blood lymphocytes were shown in vitro. ${ }^{66}$

Nanoaluminum is a strong promoter of cell death in mice, suggesting that nanoaluminum may have significant neurotoxicity, leading to impaired neurobehavioral functioning. ${ }^{67}$ Further, it has been shown that the toxicity and potential for bioaccumulation in earthworms exposed to high levels of nanoaluminum resulted in decreased reproduction. ${ }^{68}$ Although nanosized aluminum is being used widely by the military and industry in many applications, its potential for bioaccumulation might affect humans, given that they are at the top of the food chain.

\section{Chitosan nanoparticles}

Chitosan is a cationic polysaccharide that exists in nature as a major component of the outer shell of animals with exoskeletons, and is a biopolymer produced by deacetylation of chitin. Chitosan has excellent biodegradability, biocompatibility, and biosecurity, and overall nontoxic characteristics. ${ }^{69,70}$ As a carrier, nanochitosan can improve DNA and drug bioavailability, resistance in vivo to enzyme drop solutions, enhance controlled sustained release of biomaterials, reduce toxicity, and be prepared under mild conditions without the use of an organic solvent, thereby avoiding DNA and drug destruction, as well as preventing residual solvent remaining after the preparation process. ${ }^{71-73}$ Chitosan nanoparticles can be used to alter loading of a protein and to adjust the value of each parameter during preparation. They also have high stability, high protein packing efficiency, can be prepared as a lyophilized powder, and are easy to store and transport. ${ }^{74,75}$ Nanochitosan and microparticles are also suitable for tumor vaccines and have been shown to enhance antigen uptake by mucosal lymphoid tissues, thereby inducing strong responses against antigens. ${ }^{76,77}$

Nanochitosan has been reported to have a strong stimulatory effect on $\mathrm{T}$ and B lymphocytes as well as on the cellular and humoral immune systems, which can be activated at 
the same time, ${ }^{78}$ and has immune-stimulating activity by increasing accumulation and activation of macrophages and polymorphonuclear cells, and induction of cytokines after intravenous administration. ${ }^{78-80}$ All these attributes indicate that nanochitosan can be used as a carrier for cancer gene vaccines, where it has great potential application.

\section{Conclusion}

The advent of vaccines has been of the utmost significance in human health. The smallpox, hepatitis B, Bacille CalmetteGuérin, and influenza vaccines protect against viral and bacterial infection, and have saved countless lives. However, in the past ten years, although a large number of vaccines have been developed against a variety of cancers, very few have entered Phase III clinical trials. A lack of specificity for cancer cells is a major challenge for the development of cancer therapies. ${ }^{81}$

Because of their unique properties, nanomaterials are widely used in various fields, ${ }^{82}$ but their application has been less in the field of tumor vaccines. It could be possible to take advantage of their penetrating, biocompatible, targeting, immune activity, and sustained-release characteristics to make more powerful tumor vaccines, where nanomaterials would be the ideal choice for tumor vaccine carriers and adjuvants. However, some of the toxic effects of nanomaterials cannot be ignored.

Development of tumor vaccines is a multidisciplinary field, and with more indepth research on tumor biology, tumor immunology, molecular biology, and nanomaterials, a tumor vaccine will eventually be produced for the prevention and treatment of cancer.

\section{Acknowledgments}

This study was supported by grants from China National Natural Science Foundation (No.30700994 and No. 81271449), the Science and Technology Project of Shaanxi Province of China (No. 2012K17-01-01), and Xijing Hospital (No.XJZT11D05).

\section{Disclosure}

The authors report no conflicts of interest in this work.

\section{References}

1. Rosenberg SA, Yang JC, Restifo NP. Cancer immunotherapy: moving beyond current vaccines. Nat Med. 2004;10(9):909-915.

2. Shashidharamurthy R, Bozeman EN, Patel J, Kaur R, Meganathan J, Selvaraj P. Immunotherapeutic strategies for cancer treatment: a novel protein transfer approach for cancer vaccine development. Med Res Rev. 2012;32(6): 1197-1219.
3. Hale DF, Clifton GT, Sears AK, et al. Cancer vaccines: should we be targeting patients with less aggressive disease? Expert Rev Vaccines. 2012;11(6):721-731.

4. Pistoia V, Morandi F, Pezzolo A, Raffaghello L, Prigione I. MYCN: from oncoprotein to tumor-associated antigen. Front Oncol. 2012;2:174.

5. Amorij JP, Kersten GF, Saluja V, et al. Towards tailored vaccine delivery: needs, challenges and perspectives. J Control Release. 2012;161(2): 363-376.

6. Nasir A. Nanotechnology in vaccine development: a step forward. J Invest Dermatol. 2009;129(5):1055-1059.

7. Fry BN, Kalantar-Zadeh K. Nanotechnology-Enabled Sensors. New York, NY: Springer; 2008.

8. Yoon TJ, Kim JS, Kim BG, Yu KN, Cho MH, Lee JK. Multifunctional nanoparticles possessing a "magnetic motor effect" for drug or gene delivery. Angew Chem Int Ed Engl. 2005;44(7):1068-1071.

9. Yannelli JR, Wroblewski JM. On the road to a tumor cell vaccine: 20 years of cellular immunotherapy. Vaccine. 2004;23(1):97-113.

10. Tang F, Li L, Chen D. Mesoporous silica nanoparticles: synthesis, biocompatibility and drug delivery. Adv Mater. 2012;24(12): 1504-1534

11. Tan A, De La Peña H, Seifalian AM. The application of exosomes as a nanoscale cancer vaccine. Int J Nanomedicine. 2010;5:889-900.

12. Malmo J, Sandvig A, Vårum KM, Strand SP. Nanoparticle mediated P-glycoprotein silencing for improved drug delivery across the blood-brain barrier: a siRNA-chitosan approach. PLoS One. 2013;8(1):e54182.

13. Yoshioka Y, Yoshikawa T, Nabeshi H, Tsutsumi Y. Recent topics on development of nanomaterials and nano-safety science. Yakugaku Zasshi. 2013;133(2):149-150. Japanese.

14. Monteiro-Riviere NA, Tran CL. Nanotoxicology: Characterization, Dosing and Health Effects. New York, NY: Informa Healthcare; 2007.

15. Zhang WX, Karn B. Nanoscale environmental science and technology: challenges and opportunities. Environ Sci Technol. 2005; 39:94A-95A.

16. Lanone S, Boczkowski J. Biomedical applications and potential health risks of nanomaterials: molecular mechanisms. Curr Mol Med. 2006;6(6):651-663.

17. Hoshino A, Hanada S, Yamamoto K. Toxicity of nanocrystal quantum dots: the relevance of surface modifications. Arch Toxicol. 2011; 85(7):707-720.

18. Mitchell LA, Lauer FT, Burchiel SW, McDonald JD. Mechanisms for how inhaled multiwalled carbon nanotubes suppress systemic immune function in mice. Nat Nanotechnol. 2009;4(7):451-456.

19. Renwick LC, Brown D, Clouter A, Donaldson K. Increased inflammation and altered macrophage chemotactic responses caused by two ultrafine particle types. Occup Environ Med. 2004;61(5): 442-447.

20. Terrones M, Terrones $\mathrm{H}$. The carbon nanocosmos: novel materials for the twenty-first century. Philos Transact A Math Phys Eng Sci. 2003;361(1813):2789-2806.

21. Meng J, Meng J, Duan J, et al. Carbon nanotubes conjugated to tumor lysate protein enhance the efficacy of an antitumor immunotherapy. Small. 2008;4(9):1364-1370.

22. Shen H, Ackerman AL, Cody V, et al. Enhanced and prolonged cross-presentation following endosomal escape of exogenous antigens encapsulated in biodegradable nanoparticles. Immunology. 2006; 117(1):78-88.

23. Yu JS, Liu G, Ying H, Yong WH, Black KL, Wheeler CJ. Vaccination with tumor lysate-pulsed dendritic cells elicits antigen-specific, cytotoxic T-cells in patients with malignant glioma. Cancer Res. 2004; 64(14):4973-4979.

24. Salcedo M, Bercovici N, Taylor R, et al. Vaccination of melanoma patients using dendritic cells loaded with an allogeneic tumor cell lysate. Cancer Immunol Immunother. 2006;55(7):819-829.

25. Pantarotto D, Partidos CD, Hoebeke J, et al. Immunization with peptidefunctionalized carbon nanotubes enhances virus-specific neutralizing antibody responses. Chem Biol. 2003;10(10):961-966. 
26. Wadhwa PD, Zielske SP, Roth JC, Ballas CB, Bowman JE, Gerson SL. Cancer gene therapy: scientific basis. Annu Rev Med. 2002; 53:437-452.

27. Madani SY, Tan A, Dwek M, Seifalian AM. Functionalization of single-walled carbon nanotubes and their binding to cancer cells. Int $J$ Nanomedicine. 2012;7:905-914.

28. Jovanović SP, Marković ZM, Kleut DN, et al. A novel method for the functionalization of gamma-irradiated single wall carbon nanotubes with DNA. Nanotechnology. 2009;20(44):445602.

29. Gomez-Gualdrón DA, Burgos JC, Yu J, Balbuena PB. Carbon nanotubes: engineering biomedical applications. Prog Mol Biol Transl Sci. 2011;104:175-245.

30. Sánchez-Pomales G, Santiago-Rodríguez L, Cabrera CR. DNAfunctionalized carbon nanotubes for biosensing applications. J Nanosci Nanotechnol. 2009;9(4):2175-2188.

31. Kam NW, Liu Z, Dai H. Carbon nanotubes as intracellular transporters for proteins and DNA: an investigation of the uptake mechanism and pathway. Angew Chem Int Ed Engl. 2006;45(4):577-581.

32. Pantarotto D, Briand JP, Prato M, Bianco A. Translocation of bioactive peptides across cell membranes by carbon nanotubes. Chem Commun (Camb). 2004;1:16-17.

33. Klumpp C, Kostarelos K, Prato M, Bianco A. Functionalized carbon nanotubes as emerging nanovectors for the delivery of therapeutics. Biochim Biophys Acta. 2006;1758(3):404-412.

34. Villa CH, Dao T, Ahearn I, et al. Single-walled carbon nanotubes deliver peptide antigen into dendritic cells and enhance $\mathrm{IgG}$ responses to tumor-associated antigens. ACS Nano. 2011;5(7):5300-5311.

35. Kostarelos K, Bianco A, Prato M. Promises, facts and challenges for carbon nanotubes in imaging and therapeutics. Nat Nanotechnol. 2009;4(10):627-633.

36. Proffitt F. Nanotechnology. Yellow light for nanotech. Science. 2004;305(5685):762.

37. Service RF. Nanotoxicology. Nanotechnology grows up. Science. 2004;304(5678):1732-1734.

38. Manna SK, Sarkar S, Barr J, et al. Single-walled carbon nanotube induces oxidative stress and activates nuclear transcription factorkappaB in human keratinocytes. Nano Lett. 2005;5(9):1676-1684.

39. Ravichandran P, Baluchamy S, Sadanandan B, et al. Multiwalled carbon nanotubes activate NF-kappaB and AP-1 signaling pathways to induce apoptosis in rat lung epithelial cells. Apoptosis. 2010;15(12): 1507-1516.

40. Cui D, Tian F, Ozkan CS, Wang M, Gao H. Effect of single wall carbon nanotubes on human HEK293 cells. Toxicol Lett. 2005;155(1):73-85.

41. Lam CW, James JT, McCluskey R, Hunter RL. Pulmonary toxicity of single-wall carbon nanotubes in mice 7 and 90 days after intratracheal instillation. Toxicol Sci. 2004;77(1):126-134.

42. Shvedova AA, Kisin ER, Mercer R, et al. Unusual inflammatory and fibrogenic pulmonary responses to single-walled carbon nanotubes in mice. Am J Physiol Lung Cell Mol Physiol. 2005;289(5): L698-L708.

43. Oberdörster G, Sharp Z, Atudorei V, et al. Extrapulmonary translocation of ultrafine carbon particles following whole-body inhalation exposure of rats. J Toxicol Environ Health A. 2002;65(20):1531-1543.

44. Wang H, Wang J, Deng X, et al. Biodistribution of carbon singlewall carbon nanotubes in mice. J Nanosci Nanotechnol. 2004;4(8): 1019-1024.

45. Lam CW, James JT, McCluskey R, Arepalli S, Hunter RL. A review of carbon nanotube toxicity and assessment of potential occupational and environmental health risks. Crit Rev Toxicol. 2006;36(3):189-217.

46. Nel A, Xia T, Mädler L, Li N. Toxic potential of materials at the nanolevel. Science. 2006;311(5761):622-627.

47. Gulati N, Gupta H. Two faces of carbon nanotube: toxicities and pharmaceutical applications. Crit Rev Ther Drug Carrier Syst. 2012; 29(1):65-88.

48. Zhao X, Liu R. Recent progress and perspectives on the toxicity of carbon nanotubes at organism, organ, cell, and biomacromolecule levels. Environ Int. 2012;40:244-255.
49. Takegami S, Kitamura K, Kawada H, et al. Preparation and characterization of a new lipid nano-emulsion containing two cosurfactants, sodium palmitate for droplet size reduction and sucrose palmitate for stability enhancement. Chem Pharm Bull (Tokyo). 2008;56(8): 1097-1102.

50. Sakaeda T, Hirano K. O/W lipid emulsions for parenteral drug delivery. II. Effect of composition on pharmacokinetics of incorporated drug. J Drug Target. 1995;3(3):221-230.

51. Aucouturier J, Dupuis L, Ganne V. Adjuvants designed for veterinary and human vaccines. Vaccine. 2001;19(17-19):2666-2672.

52. Ge W, Sun YJ, Li Y, et al. Anti-tumor immune responses of nanoemulsion-encapsulated MHS vaccine. Xi Bao Yu Fen Zi Mian Yi Xue Za Zhi. 2008;24(5):457-460. Chinese.

53. Ge W, Hu PZ, Huang Y, et al. The antitumor immune responses induced by nanoemulsion-encapsulated MAGE1-HSP70/SEA complex protein vaccine following different administration routes. Oncol Rep. 2009;22(4):915-920.

54. Chang LC, Wu CL, Liu CW, Chuo WH, Li PC, Tsai TR. Preparation, characterization and cytotoxicity evaluation of tanshinone IIA nanoemulsions. J Biomed Nanotechnol. 2011;7(4):558-567.

55. Gasparini R, Pozzi T, Montomoli E, et al. Increased immunogenicity of the MF59-adjuvanted influenza vaccine compared to a conventional subunit vaccine in elderly subjects. Eur J Epidemiol. 2001;17(2):135-140.

56. Banzhoff A, Nacci P, Podda A. A new MF59-adjuvanted influenza vaccine enhances the immune response in the elderly with chronic diseases: results from an immunogenicity meta-analysis. Gerontology. 2003;49(3):177-184.

57. Ye J, Chen GS, Song HP, et al. Heat shock protein 70/MAGE-1 tumor vaccine can enhance the potency of MAGE-1-specific cellular immune responses in vivo. Cancer Immunol Immunother. 2004;53(9): $825-834$.

58. Ma JH, Sui YF, Ye J, et al. Heat shock protein 70/MAGE-3 fusion protein vaccine can enhance cellular and humoral immune responses to MAGE-3 in vivo. Cancer Immunol Immunother. 2005;54(9): 907-914.

59. Ge W, Sui YF, Wu DC, et al. MAGE-1/heat shock protein 70/MAGE-3 fusion protein vaccine in nanoemulsion enhances cellular and humoral immune responses to MAGE-1 or MAGE-3 in vivo. Cancer Immunol Immunother. 2006;55(7):841-849.

60. Tan Y, Yang Z, Peng X, et al. A novel bottom-up process to produce nanoparticles containing protein and peptide for suspension in hydrofluoroalkane propellants. Int J Pharm. 2011;413(1-2):167-173.

61. Bomford R. Relative adjuvant efficacy of $\mathrm{Al}(\mathrm{OH}) 3$ and saponin is related to the immunogenicity of the antigen. Int Arch Allergy Appl Immunol. 1984;75(3):80-81.

62. Mesa C, Fernández LE. Challenges facing adjuvants for cancer immunotherapy. Immunol Cell Biol. 2004;82(6):644-650.

63. Lindblad EB. Aluminium adjuvants - in retrospect and prospect. Vaccine. 2004;22(27-28):3658-3668.

64. Exley C, Siesjö P, Eriksson H. The immunobiology of aluminium adjuvants: how do they really work? Trends Immunol. 2010;31(3):103-109.

65. Sun Z, Wei W, Rui W, et al. Aluminum nano particles enhance anticancer immune response induced by tumor cell vaccine. Cancer Nanotechnology. 2010;1:63-69.

66. Maquieira Á, Brun EM, Garcés-García M, Puchades R. Aluminum oxide nanoparticles as carriers and adjuvants for eliciting antibodies from non-immunogenic haptens. Anal Chem. 2012;84(21):9340-9348.

67. Zhang QL, Li MQ, Ji JW, et al. In vivo toxicity of nano-alumina on mice neurobehavioral profiles and the potential mechanisms. Int $J$ Immunopathol Pharmacol. 2011;24(Suppl 1):23S-29S.

68. Coleman JG, Johnson DR, Stanley JK, et al. Assessing the fate and effects of nano aluminum oxide in the terrestrial earthworm, Eisenia fetida. Environ Toxicol Chem. 2010;29(7):1575-1580.

69. Shi SF, Jia JF, Guo XK, et al. Biocompatibility of chitosan-coated iron oxide nanoparticles with osteoblast cells. Int J Nanomedicine. 2012;7: 5593-5602. 
70. Upadhyaya L, Singh J, Agarwal V, Tewari RP. Biomedical applications of carboxymethyl chitosans. Carbohydr Polym. 2013;91(1):452-466.

71. Chen MC, Mi FL, Liao ZX, et al. Recent advances in chitosan-based nanoparticles for oral delivery of macromolecules. Adv Drug Deliv Rev. November 15, 2012. [Epub ahead of print.]

72. Illum L, Jabbal-Gill I, Hinchcliffe M, Fisher AN, Davis SS. Chitosan as a novel nasal delivery system for vaccines. Adv Drug Deliv Rev. 2001; 51(1-3):81-96.

73. Xu Y, Du Y. Effect of molecular structure of chitosan on protein delivery properties of chitosan nanoparticles. Int $J$ Pharm. 2003;250(1): 215-226.

74. van der Lubben IM, Kersten G, Fretz MM, Beuvery C, Coos Verhoef J, Junginger HE. Chitosan microparticles for mucosal vaccination against diphtheria: oral and nasal efficacy studies in mice. Vaccine. 2003;21(13-14):1400-1408.

75. Chen F, Shi Z, Neoh KG, Kang ET. Antioxidant and antibacterial activities of eugenol and carvacrol-grafted chitosan nanoparticles. Biotechnol Bioeng. 2009;104(1):30-39.

76. van der Lubben IM, Verhoef JC, Borchard G, Junginger HE. Chitosan and its derivatives in mucosal drug and vaccine delivery. Eur J Pharm Sci. 2001;14(3):201-207.
77. Sayin B, Somavarapu S, Li XW, et al. Mono-N-carboxymethyl chitosan (MCC) and N-trimethyl chitosan (TMC) nanoparticles for non-invasive vaccine delivery. Int J Pharm. 2008;363(1-2):139-148.

78. Seferian PG, Martinez ML. Immune stimulating activity of two new chitosan containing adjuvant formulations. Vaccine. 2000;19(6): 661-668.

79. Shibata Y, Foster LA, Metzger WJ, Myrvik QN. Alveolar macrophage priming by intravenous administration of chitin particles, polymers of N-acetyl-D-glucosamine, in mice. Infect Immun. 1997;65(5): 1734-1741.

80. Calvo P, Remuñan-López C, Vila-Jato JL, Alonso MJ. Chitosan and chitosan/ethylene oxide-propylene oxide block copolymer nanoparticles as novel carriers for proteins and vaccines. Pharm Res. 1997;14(10): 1431-1436.

81. Hong CW, Zeng Q. Awaiting a new era of cancer immunotherapy. Cancer Res. 2012;72(15):3715-3719.

82. KrishnamachariY, Geary SM, Lemke CD, Salem AK. Nanoparticle delivery systems in cancer vaccines. Pharm Res. 2011;28(2):215-236.
OncoTargets and Therapy

\section{Publish your work in this journal}

OncoTargets and Therapy is an international, peer-reviewed, open access journal focusing on the pathological basis of all cancers, potential targets for therapy and treatment protocols employed to improve the management of cancer patients. The journal also focuses on the impact of management programs and new therapeutic agents and protocols on

\section{Dovepress}

patient perspectives such as quality of life, adherence and satisfaction The manuscript management system is completely online and includes a very quick and fair peer-review system, which is all easy to use. Visit http://www.dovepress.com/testimonials.php to read real quotes from published authors. 